\title{
Longitudinal changes in body composition associated with healthy ageing: men, aged $20-96$ years
}

\author{
Andrew S. Jackson ${ }^{1 *}$, Ian Janssen ${ }^{2,3}$, Xuemei Sui ${ }^{4}$, Timothy S. Church ${ }^{5}$ and Steven N. Blair ${ }^{4,6}$ \\ ${ }^{1}$ Department of Health and Human Performance, University of Houston, Houston, TX 77204, USA \\ ${ }^{2}$ School of Kinesiology and Health Studies, Queen's University, Kingston, ON, Canada \\ ${ }^{3}$ Department of Community Health and Epidemiology, Queen's University, Kingston, ON, Canada \\ ${ }^{4}$ Department of Exercise Science, University of South Carolina, Columbia, SC, USA \\ ${ }^{5}$ Pennington Biomedical Research Center, Baton Rouge, LA, USA \\ ${ }^{6}$ Department of Epidemiology and Biostatistics, University of South Carolina, Columbia, SC, USA \\ (Submitted 18 November 2010 - Final revision received 8 June 2011 - Accepted 13 June 2011 - First published online 3 August 2011)
}

\section{Abstract}

Obesity and sarcopenia are health problems associated with ageing. The present study modelled the longitudinal changes in body composition of healthy men, aged from 20 to 96 years, and evaluated the fidelity of BMI to identify age-dependent changes in fat mass and fat-free mass. The data from 7265 men with multiple body composition determinations (total observations 38328) were used to model the age-related changes in body mass, fat mass, fat-free mass, BMI and percentage of body fat. Changes in fat mass and fat-free mass were used to evaluate the fidelity of BMI and to detect body composition changes with ageing. Linear mixed regression models showed that all trajectories of body composition with healthy ageing were quadratic. Fat mass, BMI and percentage of body fat increased from age 20 years and levelled off at approximately 80 years. Fat-free mass increased slightly from age 20 to 47 years and then declined at a non-linear rate with ageing. Levels of aerobic exercise had a positive influence on fat mass and a slight negative effect on fat-free mass. BMI and percentage of body fat were sensitive in detecting the increase in fat mass that occurred with healthy ageing, but failed to identify the loss of fat-free mass that started at age 47 years.

\section{Key words: Longitudinal changes: Ageing: BMI: Fat-free mass: Fat mass: Sarcopaenia}

BMI, the ratio of weight to height, is often used to evaluate body composition and define obesity ${ }^{(1-4)}$. Cross-sectional data from the National Health and Nutrition Examination Survey suggest two body composition trends. First, a secular trend, the prevalence of obesity among American adults has systematically increased over the past 30 years $^{(1,2,4-9)}$. Second, the prevalence of obesity increases with ageing ${ }^{(9,10)}$. The major source of BMI variation is body mass, which consists of fat mass and fat-free mass components. A limitation of using BMI to evaluate body composition is that changes can be due to either fat mass or fat-free mass.

The present focus of body composition research is on the 'obesity epidemic'(1-4). BMI is associated with the risk of all-cause mortality ${ }^{(11-14)}$ that is attenuated in the elderly. There is a growing concern about the health risks associated with the loss of fat-free mass with ageing. Longitudinal research findings document that a stable body mass of older individuals often masks body composition changes that occur in fat mass and fat-free mass components ${ }^{(15-18)}$.

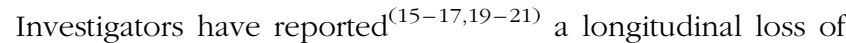
fat-free mass with ageing of older men. Sarcopenia, the loss of skeletal muscle mass, strength and function, is a growing health risk of older individuals ${ }^{(22,23)}$, which has been linked to functional impairment and physical disability ${ }^{(24,25)}$. Muscle mass makes up the majority of fat-free mass, suggesting an association between the loss in fat-free mass and sarcopenia risk.

The samples used to define the longitudinal changes in fat-free mass are restricted to older individuals, thereby limiting the generalisability of longitudinal findings ${ }^{(15-17,19-21)}$ The Aerobics Center Longitudinal Study (ACLS) cohort provides a unique opportunity to model longitudinal changes in body composition associated with healthy ageing across the adult age range. The ACLS is an open cohort study with individuals of all ages who have multiple follow-up body composition measurements. The cohort examined consisted of healthy men who completed a maximal exercise test and had their body composition measured. The goal of the present

Abbreviations: ACLS, Aerobics Center Longitudinal Study; DXA, dual-energy X-ray absorptiometry; LMM, linear mixed models; PAI, physical activity index. 
study was to model the longitudinal changes in body composition associated with healthy men aged 20-96 years. The study had four major objectives: (1) define the longitudinal changes in body mass and the body composition components of fat mass and fat-free mass; (2) model the longitudinal changes in BMI and percentage of fat with ageing; (3) define the independent role of aerobic exercise on body composition; (4) define the fidelity of BMI and percentage of fat for evaluating the changes in fat mass and fat-free mass associated with ageing.

\section{Methods \\ Study population}

The present analysis included 8099 men who received at least three comprehensive medical examinations at the Cooper Clinic in Dallas, TX, USA between 1971 and 2006. The men selected for the study completed from three to thirty-three tests (mean 5.6 tests) for a total of 45643 observations. A preliminary examination of the data revealed that the activity data before 1975 were incomplete. The 6653 tests completed from 1971 to 1974 were excluded. An additional 695 tests were excluded because the patient did not reach $85 \%$ of his age-predicted maximal heart rate during the exercise test. An additional thirty-three tests were excluded due to outliers and erroneous data. The final study sample included 7265 men with a total of 38328 observations, an average of $5 \cdot 3$ tests per individual from 1975 to 2006

The men were clinically healthy members of the ACLS. Participants came to the clinic for periodic preventive health examinations and for counselling regarding diet, exercise, weight control and other lifestyle factors associated with the increased risk of chronic disease. Participants were volunteers, not paid and not recruited to the study. Many were sent by their employers for the examination, some were referred by their physicians and others were self-referred. Participants were predominantly white, well educated, and belonged to middle and upper socio-economic strata; all had access to health care. Because we excluded individuals with major chronic diseases (heart attack, stroke and cancer), those who failed to achieve at least $85 \%$ of their estimated maximal heart rate on the treadmill test, and those with abnormal exercise tests, the study population was healthier than the general population. Participants signed an informed consent for the clinical examinations and follow-up, and the study was reviewed, approved and had ethical approval from the Institutional Review Board of the Cooper Institute.

\section{Body composition and activity methods}

Percentage of body fat was measured by either hydrostatic weighing $^{(26,27)}$ or skinfold thickness ${ }^{(28)}$, and in some instances, both. The hydrostatic weighing method measured body density and the skinfold method estimated body density from the sum of seven skinfolds and age. The reported multiple correlation for the skinfold equation ${ }^{(28)}$ was 0.90 (SEE $0 \cdot 008 \mathrm{~g} / \mathrm{cm}^{3}, 3 \cdot 4 \%$ fat). The two-component, Siri model ${ }^{(29)}$ converted the underwater measured and skinfold estimated body density to percentage of fat. When an individual had both the skinfold and underwater weighing measures, the underwater weighing method (54\%) was used. Height and weight were measured on a physician's scale and stadiometer. Body mass and percentage of body fat were used to partition body mass into its fat mass and fat-free mass components. The body composition terms studied were calculated as follows:

Fat mass $(\mathrm{kg})=($ body mass $(\mathrm{kg}) \times($ percentage of body fat $/ 100))$,

$$
\begin{gathered}
\text { Fat-freemass }(\mathrm{kg})=\operatorname{bodymass}(\mathrm{kg})-\operatorname{fatmass}(\mathrm{kg}), \\
\operatorname{BMI}\left(\mathrm{kg} / \mathrm{m}^{2}\right)=\operatorname{bodymass}(\mathrm{kg}) / \operatorname{height}(\mathrm{m})^{2} .
\end{gathered}
$$

The self-report level of aerobic exercise was assessed with a five-category physical activity index (PAI). The PAI was derived from responses to questions in the medical history questionnaire about their regular physical activity habits over the past 3 months. If they reported participation in an activity, the patient was asked to provide additional information about type of activity, times/week, the duration of each exercise session and the distance or time spent in the activity. The five PAI categories are as follows: $\mathrm{PAI}=0$, no regular activity in the past 3 months; PAI $=1$, participated in some regular physical activity such as bicycling, swimming, racquet sports and other strenuous sports, but not walking or jogging; $\mathrm{PAI}=2$, walked or jogged up to 10 miles/week; PAI $=3$, walked or jogged between 10 and 20 miles/week; PAI $=4$, walked or jogged $\geq 20$ miles/week. Walking and jogging were chosen as the basis for the PAI because it was the most common exercise mode for this population. The PAI has been discussed in greater detail in other sources ${ }^{(30-32)}$.

\section{Statistical analyses}

Linear mixed model (LMM) regression analyses were used to model the longitudinal data. A random intercept growth model used age as the measure of time ${ }^{(33,34)}$. The random intercept term accounted for dependency of the repeated tests within subjects ${ }^{(33)}$. The Stata version 11.1 xtmixed program was used for all LMM analyses (www.stata.com). The LMM analyses defined the ageing trajectories for body mass, fat mass, fat-free mass, BMI and percentage of fat. The independent variables for these models were age and age ${ }^{2}$. The level of aerobic exercise (PAI) was added to the body mass, fat mass and fat-free mass ageing models to define the influence of aerobic exercise. Activity was a categorical variable using a PAI of 0 (no regular activity in the past 3 months) as the referent category. A log-likelihood ratio test determined whether activity improved the model fit over just age ${ }^{(33)}$. Each regression coefficient was tested with a $z$-statistic to determine whether it was significantly different from $0^{(33)}$. Statistical tests were two-sided and a $P<0.05$ was accepted to indicate statistical significance.

The ACLS data were partitioned into five cohorts defined by the year of their first test: 1975-9; 1980-4; 1985-9; 1990-4; $\geq 1995$. A preliminary examination of the five first-test cohorts 
Table 1. Descriptive statistics for all observations and by age group

(Mean values and standard deviations)

\begin{tabular}{|c|c|c|c|c|c|c|c|c|c|c|c|c|}
\hline \multirow[b]{3}{*}{ Variables } & \multicolumn{10}{|c|}{ Observations by age group } & \multicolumn{2}{|c|}{ All observations } \\
\hline & \multicolumn{2}{|c|}{$<40$ years } & \multicolumn{2}{|c|}{$40-49$ years } & \multicolumn{2}{|c|}{$50-59$ years } & \multicolumn{2}{|c|}{$60-69$ years } & \multicolumn{2}{|c|}{$\geq 70$ years } & \multirow[b]{2}{*}{ Mean } & \multirow[b]{2}{*}{ SD } \\
\hline & Mean & SD & Mean & SD & Mean & SD & Mean & SD & Mean & SD & & \\
\hline Sample size $(n)$ & \multicolumn{2}{|c|}{7006} & \multicolumn{2}{|c|}{14554} & \multicolumn{2}{|c|}{12259} & \multicolumn{2}{|c|}{3976} & \multicolumn{2}{|c|}{533} & \multicolumn{2}{|c|}{38328} \\
\hline Age (years) & 35.0 & 3.7 & 44.7 & $2 \cdot 8$ & $54 \cdot 0$ & $2 \cdot 8$ & $63 \cdot 2$ & $2 \cdot 6$ & 73.0 & 3.4 & $48 \cdot 2$ & $9 \cdot 4$ \\
\hline Height $(\mathrm{cm})$ & $179 \cdot 9$ & $6 \cdot 6$ & $179 \cdot 4$ & 6.5 & $178 \cdot 8$ & $6 \cdot 2$ & $177 \cdot 8$ & $6 \cdot 3$ & $175 \cdot 8$ & $6 \cdot 2$ & $179 \cdot 1$ & $6 \cdot 4$ \\
\hline Body mass (kg) & $82 \cdot 2$ & $12 \cdot 1$ & $83 \cdot 1$ & $11 \cdot 7$ & 83.0 & $11 \cdot 0$ & $80 \cdot 6$ & $10 \cdot 2$ & $76 \cdot 7$ & $10 \cdot 1$ & $82 \cdot 6$ & 11.4 \\
\hline $\operatorname{BMI}\left(\mathrm{kg} / \mathrm{m}^{2}\right)$ & $25 \cdot 4$ & 3.2 & $25 \cdot 8$ & $3 \cdot 1$ & $26 \cdot 0$ & 3.0 & $25 \cdot 5$ & $2 \cdot 8$ & $24 \cdot 8$ & $2 \cdot 9$ & $25 \cdot 7$ & 3.0 \\
\hline Percentage of fat & $18 \cdot 1$ & $6 \cdot 0$ & $20 \cdot 2$ & $5 \cdot 6$ & $21 \cdot 7$ & $5 \cdot 2$ & $22 \cdot 0$ & $5 \cdot 1$ & $22 \cdot 1$ & 5.2 & 20.5 & $5 \cdot 6$ \\
\hline Fat mass $(\mathrm{kg})$ & $15 \cdot 3$ & 6.9 & $17 \cdot 1$ & $6 \cdot 6$ & $18 \cdot 3$ & $6 \cdot 3$ & $18 \cdot 0$ & $5 \cdot 8$ & $17 \cdot 3$ & 5.9 & $17 \cdot 3$ & $6 \cdot 6$ \\
\hline Fat-free mass (kg) & 66.9 & $7 \cdot 8$ & $66 \cdot 0$ & $7 \cdot 2$ & 64.7 & 6.8 & $62 \cdot 6$ & $6 \cdot 3$ & $59 \cdot 4$ & $6 \cdot 0$ & $65 \cdot 3$ & $7 \cdot 2$ \\
\hline $\mathrm{BMI} \geq 25 \mathrm{~kg} / \mathrm{m}^{2}(\%)$ & \multicolumn{2}{|c|}{$48 \cdot 8$} & \multicolumn{2}{|c|}{55.3} & \multicolumn{2}{|c|}{$59 \cdot 1$} & \multicolumn{2}{|c|}{53.5} & \multicolumn{2}{|c|}{39.4} & \multicolumn{2}{|c|}{54.9} \\
\hline PAI $0(\%)$ & \multirow{2}{*}{\multicolumn{2}{|c|}{$\begin{array}{l}20.6 \\
20.7\end{array}$}} & \multirow{2}{*}{\multicolumn{2}{|c|}{$\begin{array}{l}19.0 \\
2 ? .2\end{array}$}} & \multirow{2}{*}{\multicolumn{2}{|c|}{$\begin{array}{l}17.9 \\
23.1\end{array}$}} & \multirow{2}{*}{\multicolumn{2}{|c|}{$\begin{array}{l}17.5 \\
25.9\end{array}$}} & \multicolumn{2}{|c|}{23.1} & \multicolumn{2}{|c|}{$18 \cdot 9$} \\
\hline PAI 1 (\%) & & & & & & & & & \multirow{2}{*}{\multicolumn{2}{|c|}{$26 \cdot 3$}} & \multirow{2}{*}{\multicolumn{2}{|c|}{$\begin{array}{l}22 \cdot 6 \\
29 \cdot 6\end{array}$}} \\
\hline PAI 2 (\%) & \multicolumn{2}{|c|}{$31 \cdot 2$} & \multicolumn{2}{|c|}{29.5} & \multicolumn{2}{|c|}{29.9} & \multicolumn{2}{|c|}{$27 \cdot 2$} & & & & \\
\hline PAI 3 (\%) & & & & & & & & & & & & \\
\hline PAI 4 (\%) & & & & & & & & & & & & \\
\hline
\end{tabular}

PAI, physical activity index.

documented a secular body composition trend. Mean age and height for observations varied slightly over the five cohorts ( \pm 2.5 years and $\pm 1 \mathrm{~cm}$ ) while body mass, BMI, percentage of fat and fat mass systematically increased $(P<0 \cdot 001)$. Therefore, first-test cohort was used as a random part of each LMM to control for the secular trend ${ }^{(33,34)}$

\section{Results}

Table 1 gives the descriptive statistics for all observations and categorised by age group. The men ranged in age from 20 to 96 years. Height decreased across the age groups. Body mass, BMI and fat-free mass were lower for men $\geq 60$ years. Percentage of fat and fat mass increased across the age groups. Fatfree mass increased up to age 50 years and then decreased. The proportion of overweight or obese (BMI $\geq 25 \mathrm{~kg} / \mathrm{m}^{2}$ ) men varied from a high of $57 \%$ for men aged 50-59 years and a low of $37 \%$ for men aged $\geq 70$ years. Trends in PAI by age group did not appear to be evident. The percentage of active men (PAI $\geq 3$ ) ranged from $27.4 \%$ for men aged less than 40 years to $29 \cdot 3 \%$ for men aged 60-69 years. Nearly $28 \%$ of men aged $\geq 70$ years reported they walked or jogged $\geq 10$ miles/week.

Table 2 gives the longitudinal ageing models of the body composition variables. Provided are the maximum-likelihood estimates of the LMM regression weights $(\beta)$ and the $95 \%$ CI of each weight. The quadratic model provided a more accurate fit $(P<0.0001)$ than a linear model for all body composition variables. Figs. 1 and 2 illustrate the ageing trajectories for the body composition components defined by these models. Table 3 provides the estimated body composition at age 20 years and the estimated decade change for each body composition variable. Fig. 1 shows that body mass increased with ageing and levelled off at age 69 years and decreased at a non-linear rate with ageing. Table 3 shows that the loss of body mass was 0.80 and $1.97 \mathrm{~kg}$ in the seventh and eighth decades, respectively. Fat mass increased with ageing, levelled off and then decreased slightly $(0.25 \mathrm{~kg}$, approximately 0.6 pounds) in the eighth decade. Fat-free mass increased slightly from age 20 to 47 years and then decreased. Table 3 shows that fat-free mass decreased to $0.42 \mathrm{~kg}$ in the fifth decade that progressively increased to $1.96 \mathrm{~kg}$ in the eighth decade. Percentage of fat and BMI increased at non-linear rates and levelled off at age 88 years for percentage of fat and 77 years for BMI. Percentage of fat increased in each age decade while BMI increased with age until the eighth decade where it decreased slightly, $-0 \cdot 13 \mathrm{~kg} / \mathrm{m}^{2}$.

Table 4 provides the maximum-likelihood estimates ( $\beta, 95 \%$ $\mathrm{CI}$ ) of the ageing and physical activity models. A log-likelihood

Table 2. Maximum-likelihood regression estimates defining the longitudinal body composition quadratic ageing trajectories of men (Regression estimates and 95\% confidence intervals)

\begin{tabular}{|c|c|c|c|c|c|c|}
\hline \multirow[b]{2}{*}{ Variables } & \multicolumn{2}{|c|}{ Constant } & \multicolumn{2}{|r|}{ Age } & \multicolumn{2}{|r|}{$\mathrm{Age}^{2}$} \\
\hline & $\beta$ & $95 \% \mathrm{Cl}$ & $\beta$ & $95 \% \mathrm{Cl}$ & $\beta$ & $95 \% \mathrm{Cl}$ \\
\hline Body mass $(\mathrm{kg})$ & $59 \cdot 1131^{*}$ & $58 \cdot 0159,60 \cdot 2104$ & $0.7973^{\star}$ & $0.75432,0.84037$ & $-0.0058^{\star}$ & $-0.0063,-0.0054$ \\
\hline Fat mass $(\mathrm{kg})$ & -0.3566 & $-1.3569,0.6438$ & $0.5417^{*}$ & $0.5015,0.5819$ & $-0.0033^{*}$ & $-0.0037,-0.0029$ \\
\hline Fat-free mass $(\mathrm{kg})$ & $60.3428^{*}$ & $59.5200,61.1656$ & $0.2384^{*}$ & $0.2058,0.2711$ & $-0.0026^{\star}$ & $-0.0029,-0.0023$ \\
\hline BMI $\left(\mathrm{kg} / \mathrm{m}^{2}\right)$ & $19 \cdot 3111^{*}$ & $18.9670,19.6553$ & $0.2009^{\star}$ & $0.1873,0.2145$ & $-0.0013^{\star}$ & $-0.0014,-0.0011$ \\
\hline Percentage of fat & $5 \cdot 1705^{\star}$ & $4 \cdot 1833,6 \cdot 1577$ & $0.4527^{\star}$ & $0.4127,0.4926$ & $-0.0026^{*}$ & $-0.0030,-0.0022$ \\
\hline
\end{tabular}

* Coefficients were significantly different $(P<0.001)$. 


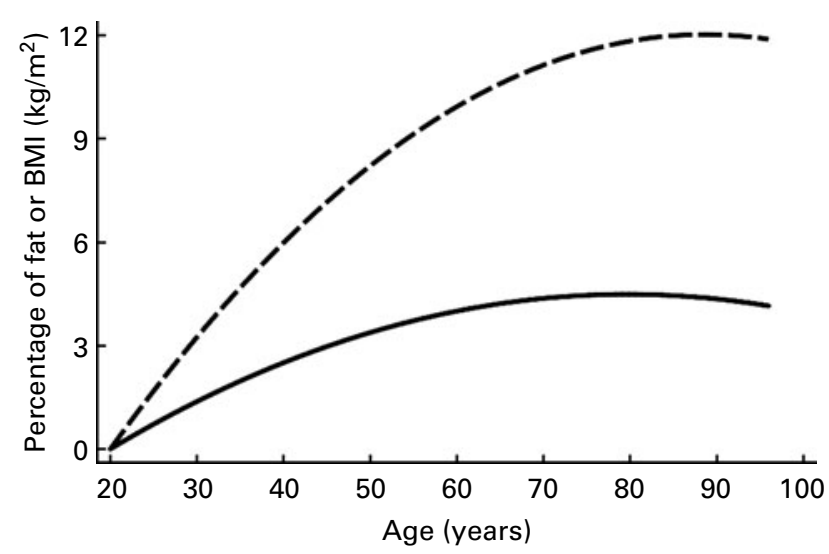

Fig. 1. Linear mixed model (LMM) quadratic regression lines that define the longitudinal change in BMI (-) and percentage of fat (----) from age 20 years. The BMI and percentage of fat LMM estimates for age 20 years were $22.83 \mathrm{~kg} / \mathrm{m}^{2}$ and $13.20 \%$, respectively.

ratio test confirmed that adding activity to the quadratic age models improved the fit $(P<0.0001)$ for all body composition components, but the effect for body and fat mass differed from that for fat-free mass. After controlling for age, each PAI regression coefficient for body mass and fat mass was statistically significant. Each PAI increase in physical activity was associated with a greater weight loss. The largest coefficients were for PAI levels 3 and 4 . Body mass and fat mass regression weights for the PAI level 4 were identical, $-2 \cdot 30$, demonstrating that after controlling for age, men who walked or jogged $\geq 20$ miles/week were approximately 5 pounds $(2 \cdot 3 \mathrm{~kg})$ lighter than those who were inactive $(\mathrm{PAI}=0)$. The body and fat mass of those active at the PAI 3 level was approximately $1.3 \mathrm{~kg}$ (approximately 2.9 pounds) lower than that of inactive men. The coefficients for PAI levels 1 and 2 were significant, but low, ranging from -0.52 to $-0.69 \mathrm{~kg}$. There was a significant PAI effect $(P<0 \cdot 001)$ for fat-free mass that was traced to the PAI levels 3 and 4. After controlling for age, the most active men $(\mathrm{PAI} \geq 3$ ) had less fat-free mass than inactive men, but the effect was small. The fat-free mass of those

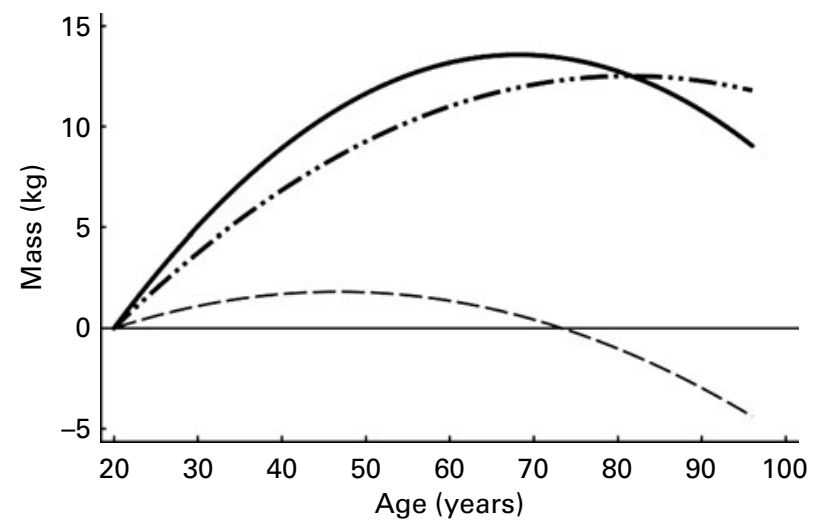

Fig. 2. Linear mixed model (LMM) quadratic regression lines that define the longitudinal change in body mass (_) and the fat mass (.........) and fatfree mass (----) components from age 20 years. The estimated mass values at age 20 years were as follows: body mass, $72.72 \mathrm{~kg}$; fat mass, $9.14 \mathrm{~kg}$; fat-free mass, $64.09 \mathrm{~kg}$. active at the PAI levels 3 and 4 was $0.16 \mathrm{~kg}$ (approximately 0.35 pounds) and $0.26 \mathrm{~kg}$ (approximately 0.57 pounds), respectively, lower than those less active $(\mathrm{PAI} \leq 2)$

\section{Discussion}

These longitudinal results confirmed that changes in body composition associated with healthy ageing were quadratic, but the trajectories of change differed. Fat mass increased with ageing and levelled off at approximately 70 years. Fatfree mass increased slightly between age 20 and 47 years, and then steadily decreased at a non-linear rate with ageing. The modelled loss in fat-free mass between 50 and 89 years was $4 \mathrm{~kg}$ ( 10.5 pounds), and approximately $40 \%$ of the loss was in the eighth decade. The ageing trajectory for body mass increased from age 20 to 60 years, levelled off and then decreased with ageing. The increase in body mass was primarily due to the increase in fat mass and the decline after age 70 years was due to the loss of fat-free mass. The ageing trajectories for BMI and percentage of fat were similar; they increased to about age 70 years and levelled off. Neither BMI nor percentage of fat identified the decline in fat-free mass with ageing. After about age 60 years, changes in percentage of fat became more of a function of the loss of fat-free mass than the increase in fat mass. In the eighth decade, percentage of fat increased by approximately $0.2 \%$ and fat mass decreased by $0.25 \mathrm{~kg}$. The increase in percentage of fat was due to the $1.96 \mathrm{~kg}$ ( 4.3 pounds) decrease in fat-free mass.

A major strength of these ACLS results is the modelled ageing trajectories which were defined with data across the adult lifespan. Other investigators ${ }^{(15,16,19,20,35)}$ using longitudinal data with restricted age ranges have reported fat-free mass decreases with ageing. Investigators of the Fels Longitudinal Study have reported that fat-free mass declined at a linear rate of $0.07 \mathrm{~kg} /$ year for men aged $40-66$ years $^{(20)}$. The ACLS fat-free mass quadratic model estimated a similar rate of decline of $0.06 \mathrm{~kg} /$ year to the Fels data. Hughes et al. ${ }^{(16)}$ reported that men lost an average of $1.1 \mathrm{~kg}$ of fat-free mass between the age of 61 and 71 years. The ACLS modelled fat-free mass loss between these ages was estimated to be $1.4 \mathrm{~kg}$. Ding et al. ${ }^{(19)}$ studied men aged 70-79 years and reported that fat-free mass measured with dual-energy X-ray absorptiometry (DXA) declined at a quadratic rate over the 6 years of serial testing. Similar to these ACLS findings, Fleg et $a l .{ }^{(35)}$ reported that fat-free mass remained stable at a young age, but started an accelerated decline at about age 50 years and that the age-related change in body composition was due to the rapid loss of fat-free mass with ageing. Interestingly, although the ACLS men examined in the present study were quite healthy relative to the cohorts examined in the previous literature ${ }^{(15,16,19,20,35)}$, the rate and patterns of fat-free mass loss were quite comparable, supporting the fidelity and generalisability of the fat-free mass model.

Cross-sectional and longitudinal results ${ }^{(15,36)}$ suggest that the age-related decline in fat-free mass was largely a function of the loss of appendicular muscle mass. Gallagher et al. ${ }^{(15)}$ examined appendicular muscle mass loss of men after age 60 years using regional body composition estimates obtained 
Table 3. Linear mixed model (LMM) change in body composition from age 20 years for each age decade of men

\begin{tabular}{lcccrc}
\hline Age decade (years) & Body mass $(\mathrm{kg})$ & Fat mass $(\mathrm{kg})$ & Fat-free mass $(\mathrm{kg})$ & $\mathrm{BMl}\left(\mathrm{kg} / \mathrm{m}^{2}\right)$ & Percentage of fat \\
\hline Age $20^{*}$ & 72.72 & 9.14 & 64.09 & 22.83 & $13 \cdot 20$ \\
$20-29$ & 5.05 & 3.75 & 1.11 & 1.38 & 3.25 \\
$30-39$ & 3.88 & 3.08 & 0.60 & 1.13 & $2 \cdot 74$ \\
$40-49$ & 2.71 & 2.42 & 0.09 & 0.87 & 2.23 \\
$50-59$ & 1.54 & 1.75 & -0.42 & 0.62 & 1.72 \\
$60-69$ & 0.37 & 1.08 & -0.94 & 0.37 & 1.21 \\
$70-79$ & -0.80 & 0.42 & -1.45 & 0.12 & 0.70 \\
$80-89$ & -1.97 & -0.25 & -1.96 & -0.13 & 0.19
\end{tabular}

* LMM estimated value at age 20 years.

with DXA. They reported that the 5-year decline in total DXA fat-free mass was $1.4 \mathrm{~kg}$. The DXA regional measures defined the loss of total appendicular muscle mass at $0.8 \mathrm{~kg}$, of which $0.7 \mathrm{~kg}$ was the loss of leg muscle mass. Janssen et al. ${ }^{(36)}$ reported a cross-sectional quadratic ageing decline in skeletal muscle mass measured by MRI. The reported decline in the lower body muscle mass of $0.063 \mathrm{~kg} /$ year was over two times greater than the upper body loss of $0.029 \mathrm{~kg} /$ year.

These ACLS results showed that aerobic exercise was associated with a lower fat-free mass than that of inactive men, but the effect was small and consistent with longitudinal and cross-sectional data ${ }^{(17,37)}$. There is evidence that physical activity attenuates weight loss in older individuals. Stephen \& Janssen ${ }^{(38)}$ reported that the weight of older individuals who were active at their initial visit was lower than those who were inactive, but over the 8 years of follow-up, the active individuals lost $2.4 \mathrm{~kg}$ less weight than those who were inactive. The age-related weight-loss trajectory of those who did not survive to the 9th year of follow-up was steeper than the survivors. Dziura et al. ${ }^{(39)}$ reported that the loss of weight in older individuals ( $>65$ years) increased with ageing, but increases in exercise frequency attenuated the rate of decline. The weight-loss trajectory of those who did not survive the 12 years of follow-up was steeper than the survivors. Flicker et $a l .{ }^{(40)}$ reported that in 10 years of follow-up, older men ( $\geq 70$ years) who were sedentary had a $28 \%$ higher risk of all-cause mortality than men who reported they walked or jogged.

These ACLS findings show that aerobic exercise does not prevent the loss of fat-free mass. Fleg et al. ${ }^{(35)}$ suggest that strength training is needed to preserve the fat-free mass of older individuals. In a review of eighteen studies, Doherty ${ }^{(22)}$ reported that the median knee extensor strength of men aged $\geq 70$ years was $67.5 \%$ of a young adult referent group and resistance training was effective in increasing the strength of older people. Doherty ${ }^{(22)}$ reported that the one-repetition maximum strength gains produced with resistance training ranged from 26 to $152 \%$ (median 39\%) for thirteen studies of men and women, aged 60 years and older. These results suggest that while aerobic exercise does not influence the loss of fat-free mass associated with ageing, resistance training may.

The physiological basis for using BMI to evaluate body composition is based on moderate correlations ( $r$ approximately 0.60 ) between BMI and percentage of body fat ${ }^{(41)}$ The wide use of BMI to evaluate body composition is probably due to the availability of body mass and height data in a variety of research settings. While BMI has been shown to predict the risk of all-cause mortality in the general population ${ }^{(11-14)}$, its fidelity with older populations is dubious. There is evidence that BMI does not predict mortality risk within individuals aged $\geq 70$ years unless they were also obese at age 50 years or younger ${ }^{(40,42,43)}$. An earlier report $^{(44)}$ from the ACLS showed that BMI and body composition were associated with higher mortality risk in women and men aged $\geq 60$ years. However, in this report, the associations with BMI and body composition were eliminated after adjusting for cardiorespiratory fitness. The present findings from the ACLS demonstrated that the stability of BMI and percentage of fat of healthy older men masked changes in body composition, largely due to the non-linear decline in fat-free mass with ageing. These results are consistent with research showing that the stable body mass of older individuals of a restricted age range masked changes in fat mass and fat-free mass components ${ }^{(15-18)}$.

Table 4. Maximum-likelihood regression estimates for age and the level of aerobic exercise of men

(Regression estimates and 95\% confidence intervals)

\begin{tabular}{|c|c|c|c|c|c|c|c|c|c|}
\hline \multirow[b]{2}{*}{ Variables } & \multicolumn{3}{|c|}{ Body mass } & \multicolumn{3}{|c|}{ Fat mass } & \multicolumn{3}{|c|}{ Fat-free mass } \\
\hline & $\beta$ & $95 \% \mathrm{Cl}$ & $P$ & $\beta$ & $95 \% \mathrm{Cl}$ & $P$ & $\beta$ & $95 \% \mathrm{Cl}$ & $P$ \\
\hline Constant & $59 \cdot 3014$ & $58 \cdot 2146,60 \cdot 3883$ & $<0.0001$ & -0.0071 & $-1.0624,0.9204$ & 0.888 & $60 \cdot 3089$ & $59 \cdot 485,61 \cdot 1321$ & $<0.0001$ \\
\hline Age & 0.8245 & $0.7818,0.8671$ & $<0.0001$ & 0.5670 & $0.5271,0.6069$ & $<0.0001$ & 0.2414 & $0.2087,0.2741$ & $<0.0001$ \\
\hline $\mathrm{Age}^{2}$ & -0.0062 & $-0.0066,-0.0057$ & $<0.0001$ & -0.0036 & $-0.0040,-0.0032$ & $<0.0001$ & -0.0026 & $-0.0029,-0.0023$ & $<0.0001$ \\
\hline PAI 1 & -0.5183 & $-0.6351,-0.4014$ & $<0.0001$ & -0.5567 & $-0.6687,-0.4447$ & $<0.0001$ & 0.0055 & $-0.0843,0.0953$ & 0.905 \\
\hline PAI 2 & -0.5657 & $-0.6787,-0.4529$ & $<0.0001$ & -0.6940 & $-0.8021,-0.5858$ & $<0.0001$ & 0.0518 & $-0.0351,0.1388$ & 0.243 \\
\hline PAI 3 & -1.3230 & $-1.4539,-1.1921$ & $<0.0001$ & -1.3023 & $-1.4273,-1.1773$ & $<0.0001$ & -0.15984 & $-0.2606,-0.0591$ & $<0.0001$ \\
\hline PAI 4 & $-2 \cdot 3048$ & $-2 \cdot 4770,-2 \cdot 1326$ & $<0.0001$ & $-2 \cdot 3005$ & $-2 \cdot 4643,-2 \cdot 1367$ & $<0.0001$ & -0.2636 & $-0.3960,-0.1312$ & $<0.0001$ \\
\hline
\end{tabular}

PAl, physical activity index. 
An important finding of the present study is that the modelled ageing change in fat-free mass was not detected by modelled changes in BMI and percentage of body fat. What is unanswered is the association between the loss of fat-free mass and the risk of sarcopenia. The diagnostic criteria for age-related sarcopenia include both low muscle mass and low muscle function involving both strength and performance ${ }^{(45)}$. While muscle makes up the majority of the fat-free mass body compartment of these ACLS data, it also includes organs and bone. Most of the loss in fat-free mass with ageing is due to skeletal muscle, but would also include contributions from organs and bone. Sarcopenia is a growing health risk associated with functional impairment and physical disability in ageing populations ${ }^{(22-25)}$. These ACLS results suggest that age-related changes in fat-free mass may be a valid screening tool to identify individuals at risk of sarcopenia, but awaits validation research.

The major strength of the present study was the use of a very large sample of healthy men ranging in age from 20 to 96 years with multiple body composition measures over time. The multiple data points allowed us to define longitudinal changes in body composition representative of healthy ageing across the adult age range of men. The LMM is an ideal statistical method to model longitudinal data where subjects have a different number of tests at different times because it accommodates unbalanced and unequally spaced observations over time $e^{(33,34)}$.

A limitation of the study was that percentage of fat was measured by two different methods. Post boc analysis showed that there was a significant intercept difference $(P<0 \cdot 001)$ between the underwater weighing and skinfold methods. The underwater weighing measure was systematically lower than the skinfold estimate, but the effect was small, $-0 \cdot 13 \%$ fat $(95 \%$ CI $-0.20,-0.06)$. An examination of the skinfold and underwater residuals (measured - estimated percentage of fat) showed that the distributions of the skinfold and underwater weighing residuals were similar and normally distributed. The means and standard deviations of the residuals were -0.029 (SD 2.839) and 0.034 (SD2.610) for the underwater weighing and skinfold methods. An examination of the bivariate distribution (data not shown) showed that the residuals for both methods were evenly distributed across age, supporting the validity of the underwater and skinfold methods

The findings of the present study can only be generalised to the LMM fixed effects of ageing and self-report physical activity for a sample representative of healthy ageing. The models accurately define the ageing changes in body composition for a population of men, but lack accuracy in defining the changes in individuals. There are variables other than ageing and activity that influence weight change over time (e.g. variation in diet). Intra-class analyses ${ }^{(33)}$ of the body mass LMM variance components found that $94 \%$ of the body mass variance was not explained by ageing and self-report aerobic exercise, but by other sources of variability within men over time.

In summary, the relationship between ageing and body composition of healthy men is quadratic. The increase in body mass from age 20 to approximately 70 years is primarily due to increases in fat mass and the decrease after age 70 years is associated with the loss of fat-free mass. Aerobic exercise has a positive influence on lowering fat mass, but does not prevent the loss of fat free mass with ageing. Neither BMI nor percentage of fat was sensitive in detecting the age-related loss of fat-free mass. Using BMI or percentage of fat to evaluate changes in body composition of older men masks the loss of fat-free mass associated with ageing of healthy men.

\section{Acknowledgements}

The present study was supported by the National Institutes of Health grants AG06945, HL62508 and R21DK088195. The content is solely the responsibility of the authors and does not necessarily represent the official views of the National Institutes of Health. We thank the Cooper Clinic physicians and technicians for collecting the baseline data, and staff at the Cooper Institute for data entry and data management. A. S. J., I. J., T. S. C. and S. N. B. designed the research; T. S. C. and S. N. B. conducted the research; X. S. and A. S. J. analysed the data or performed the statistical analysis. A. S. J., T. S. C., X. S. and S. N. B. had primary responsibility for the final content. There are no conflicts of interest.

\section{References}

1. Kuczmarski R \& Flegal KM (2000) Criteria for definition of overweight in transition: background and recommendations for the United States. Am J Clin Nutr 72, 1075-1081.

2. Kuczmarski RJ, Flegal KM, Campbell SM, et al. (1994) Increasing prevalence of overweight among US adults. JAMA 272, 205-211.

3. World Health Organization (1995) Physical Status: The Use and Interpretation of Anthropometry. Technical Report Series no. 854. Geneva: WHO.

4. World Health Organization (1998) Obesity: Preventing and Managing the Global Epidemic. Report of a WHO Consultation on Obesity. Geneva: WHO.

5. Hedley AA, Ogden CL, Johnson CL, et al. (2004) Prevalence of overweight and obesity among US children, adolescents, and adults. JAMA 291, 2847-2850.

6. Flegal K \& Troiano RP (2000) Changes in the distribution of body mass index of adults and children in the US population. Int J Obes 24, 807-818.

7. Flegal KM, Carroll MD, Ogden CL, et al. (2002) Prevalence and trends in obesity among US adults 1999-2000. JAMA 288, 1723-1727.

8. Ogden C, Carrol MD, Curtin LR, et al. (2006) Prevalence of overweight and obesity in the United States, 1999-2004. JAMA 295, 1549-1555.

9. Ogden CL, Fryar FC, Carroll MD, et al. (2004) Mean body weight, height, and body mass index, United States 1960-2002. In Vital and Health Statistics CDC, pp. 1-17: US Department of Health and Human Services. Washington, DC: CDC, National Center for Health Statistics.

10. Chumlea WC, Guo SS, Kuczmarski RJ, et al. (2002) Body composition estimates from NHANES III bioelectrical impedance data. Int J Obes 26, 1596-1609. 
11. Flegal KM, Graubard BI, Williamson DF, et al. (2005) Excess deaths associated with underweight, overweight, and obesity. JAMA 293, 1861-1867.

12. Flegal KM, Graubard BI, Williamson DF, et al. (2007) Cause-specific excess deaths associated with underweight, overweight, and obesity. JAMA 298, 2028-2037.

13. Fontaine KR, Redden DT, Wang C, et al. (2003) Years of life lost due to obesity. JAMA 289, 187-193.

14. Neovius M, Sundstrom I \& Rasmussen F (2009) Combined effects of overweight and smoking in late adolescence on subsequent mortality: nationwide cohort study. BMJ 38, 338-444.

15. Gallagher D, Ruts E, Visser M, et al. (2000) Weight stability masks sarcopenia in elderly men and women. Am J Physiol Endocrinol Metab 279, E366-E375.

16. Hughes VA, Frontera WR, Roubenoff R, et al. (2002) Longitudinal changes in body composition in older men and women: role of body weight change and physical activity. Am J Clin Nutr 76, 473-481.

17. Raguso CA, Kyle U, Kossovsky MP, et al. (2006) A 3-year longitudinal study on body composition changes in the elderly: role of physical exercise. Clin Nutr $\mathbf{2 5}$, 573-580.

18. Zamboni M, Zoico E, Scartezzini T, et al. (2003) Body composition changes in stable-weight elderly subjects: the effect of sex. Aging Clin Exp Res 15, 321-327.

19. Ding J, Kritchevsky SB, Newman AB, et al. (2007) Effects of birth cohort and age on body composition in a sample of community-based elderly. Am J Clin Nurt 85, 405-410.

20. Guo SS, Zeller C, Chumlea WC, et al. (1999) Aging, body composition, and lifestyle: the Fels Longitudinal Study. Am J Clin Nutr 70, 405-411.

21. Lee JS, Visser M, Tylavsky FA, et al. (2010) Weight loss and regain and effects on body composition: the health, aging, and body composition study. J Gerontol A Biol Sci Med Sci 65A, $78-83$.

22. Doherty TJ (2003) Aging and sarcopenia. J Appl Physiol 95, $1717-1727$

23. Waters DL, Baumgartner RN, Garry PJ, et al. (2010) Advantages of dietary, exercise-related, and therapeutic interventions to prevent and treat sarcopenia in adult patients: an update. Clin Interv Aging 5, 259-270.

24. Janssen I, Heymsfield SB \& Ross R (2002) Low relative skeletal muscle mass (sarcopenia) in older persons is associated with functional impairment and physical disability. JAGS $\mathbf{5 0}$, 889-896.

25. Manini TM, Everhart JE, Anton SD, et al. (2009) Activity energy expenditure and change in body composition in late life. Am J Clin Nurtr 90, 1336-1342.

26. Behnke AR \& Wilmore JH (1974) Evaluation and Regulation of Body Build and Composition. Englewood Cliffs, NJ: Prentice Hall.

27. Going SB (2005) Densitometry. In Human Body Composition, 2nd ed., pp. 17-34 [SB Heymsfield, TG Lohnman, $Z$ Wang and SB Going, editors]. Champaign, IL: Human Kinetics.
28. Jackson AS \& Pollock ML (1978) Generalized equations for predicting body density of men. Br J Nutr $\mathbf{4 0}$, 497-504.

29. Siri WE (1961) Body composition from fluid space and density. In Techniques for Measuring Body Composition, pp. 223-244 [J Brozek and A Hanschel, editors]. Washington, DC: National Academy of Science.

30. Cheng YJ, Macera CA, Davis DR, et al. (2000) Physical activity and self-reported, physician-diagnosed osteoarthritis: is physical activity a risk factor? J Clin Epidemiol 53, 315-322

31. Jackson AS, Sui X, Hébert JR, et al. (2009) Role of lifestyle and aging on the longitudinal change in cardiorespiratory fitness. Arch Intern Med 169, 1781-1787.

32. Kampert JB, Blair SN, Barlow CE, et al. (1996) Physical activity, physical fitness, and all-cause and cancer mortality: a prospective study of men and women. Ann Epidemiol 6, 452-457.

33. Rabe-Hesketh S \& Skrondal A (2008) Multilevel and Longitudinal Modeling Using Stata, 2nd ed. College Station, TX: Stata Press.

34. West B, Welch KB \& Gatecki AT (2007) Linear Mixed Models. New York: Chapman \& Hall/CRC.

35. Fleg JL, Morrell CH, Bos AG, et al. (2005) Accelerated longitudinal decline of aerobic capacity in healthy older adults Circulation 112, 674-682.

36. Janssen I, Heymsfield SB, Wang Z, et al. (2000) Skeletal muscle mass and distribution in 468 men and women aged 18-88 yr. J Appl Physiol 89, 81-88.

37. Mitchell D, Haan M, Steinberg FM, et al. (2003) Body composition in the elderly: the influence of nutritional factors and physical activity. J Nutr Health Aging 7, 130-139.

38. Stephen WC \& Janssen I (2010) Influence of physical activity on age-related weight loss in the elderly. JPAH 7, 78-86.

39. Dziura J, Mendes de Leon CM, Kasl S, et al. (2004) Can physical activity attenuate aging-related weight loss in older people? Am J Epidemiol 159, 759-767.

40. Flicker LP, McCaul KA, Hankey GJ, et al. (2010) Body mass index and survival in men and women aged 70 to 75 . $J$ Am Geriatr Soc 58, 234-241.

41. Jackson AS, Stanforth PR, Gagnon J, et al. (2002) The effect of sex, age, and race on estimating percent body fat from BMI: the HERITAGE Family Study. Int J Obes 26, 789-796.

42. Janssen I, Heymsfield SB, Baumgartner RN, et al. (2000) Estimation of skeletal muscle mass by bioelectrical impedance analysis. $J$ Appl Physiol 89, 465-471.

43. Stessman J, Jacobs JM, Ein-Mor E, et al. (2009) Normal body mass index rather than obesity predicts greater mortality in elderly people: the Jerusalem Longitudinal Study. $\mathrm{J} \mathrm{Am}$ Geriatr Soc 57, 2232-2238.

44. Sui X, LaMonte MJ, Laditka JN, et al. (2007) Cardiorespiratory fitness and adiposity as mortality predictors in older adults. JAMA 5, 2507-2516.

45. Cruz-Jentoft AJ, Baeyens JP, Bauer JM, et al. (2010) Sarcopenia: European consensus on definition and diagnosis: Report of the European Working Group on Sarcopenia in Older People. Age Ageing 4, 412-423. 